\title{
Double-ended Pseudocomedones in Hidradenitis Suppurativa: Clinical, Dermoscopic, and Histopatho- logical Correlation
}

Francesco LACARRUBBA, Maria Letizia MUSUMECI, Maria Rita NASCA, Anna Elisa VERZì, Federica FIORENTINI and Giuseppe MICALI*

Dermatology Clinic, University of Catania, A.O.U. Policlinico-Vittorio Emanuele, Via Santa Sofia, 78, IT-95123, Catania, Italy. *E-mail: cldermct@gmail.com

Accepted Dec 15, 2016; Epub ahead of print Dec 16, 2016

Hidradenitis suppurativa (HS) is a chronic inflammatory disease of the pilosebaceous unit, affecting skin areas rich in apocrine glands and their surrounding tissues, clinically characterized by the presence of deep-seated and painful nodules or abscesses, draining sinuses and prominent scarring (1). Double-ended pseudocomedones (DEP) are also considered a typical clinical sign of this disorder (2). The aim of this study is to evaluate the clinical, dermoscopic, and histopathological features of DEP in order to identify a clinicopathological correlation.

\section{MATERIALS AND METHODS}

A total of 37 patients ( 9 males, 28 females, age range 9-52 years, mean age 30.9 years) with current or past evidence of HS were evaluated for the presence of DEP. All subjects provided informed consent to their participation in the study. Sixty-four DEP from 20 patients ( 5 males,

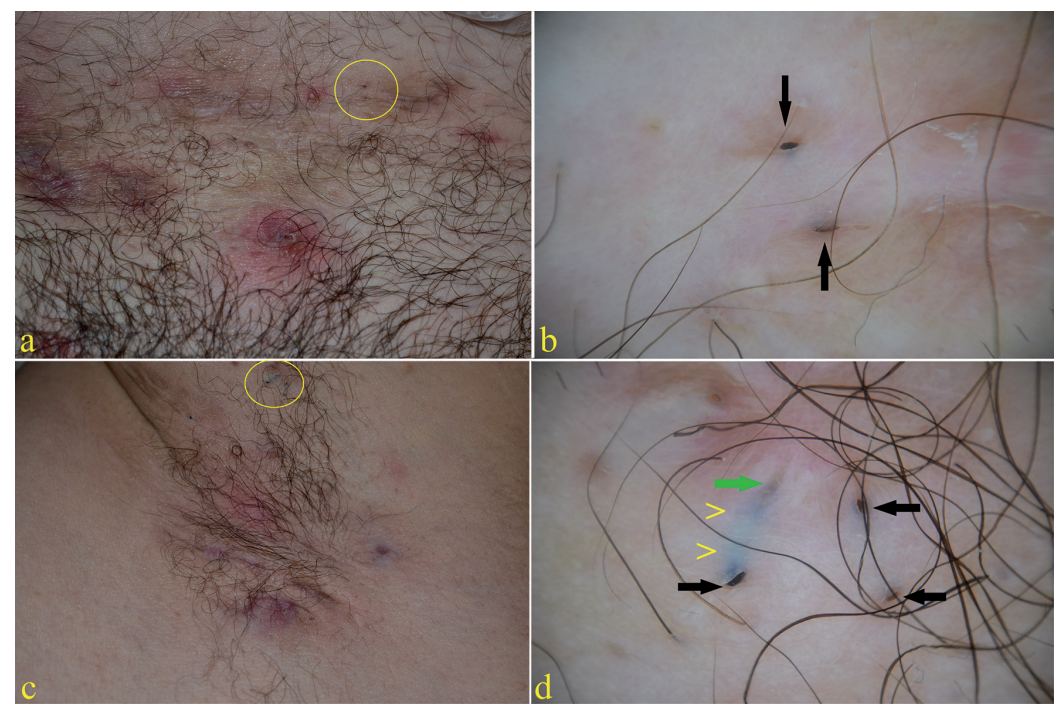

Fig. 1. Clinical and dermoscopic aspects of double-ended pseudocomedones. Two cases (Nos. 8 and 6) of hidradenitis suppurativa (a and c) with pseudocomedones (yellow circles). Under polarized light dermoscopy (b and d), multiple keratin accumulation, either superficially located (black arrows) or deep-seated (green arrow), may be observed embedded in whitish cicatricial tissue. Some appear to be connected via a bluish tunnel (arrowheads).
15 females, age range $8-52$ years, mean age 33.8 years) (Table $\mathrm{SI}^{1}$ ), were clinically identified and evaluated by dermoscopy at $\times 10$ using polarized (Dermlite hybrid ${ }^{\circledR}, 3$ Gen, San Juan Capistrano, CA, USA) and incident light (KH-1300, Hirox, Hackensack, USA). In 2 cases a skin biopsy was performed.

\section{RESULTS}

There were multiple DEP in 14 patients (mean 4.1 DEP/ patient, range $2-8$ ), with 6 patients only showing a single DEP $\left(\right.$ Table $\left.\mathrm{SI}^{1}\right)$. Clinically, DEP generally presented as coupled tiny cavities, usually showing a blackhead at each end (Figs 1a, c; 2a, d). Preferential localizations were those typical of HS, namely genito-femoral region (21 lesions), axillae (18 lesions), lower abdomen (14 lesions), buttocks (9 lesions) and mammary region (2 lesions).

Under polarized light dermoscopy, DEP appeared as coupled hollows deepening in a slanted or parallel fashion with respect to the skin surface. The hollows were always observed within a whitish cicatricial tissue of variable depth and morphology (atrophic, bridging, and circinate

${ }_{1}$ https://www.medicaljournals.se/acta/content/abstract/10.2340/00015555-2601 scars), and generally presented large, irregular openings with ragged and/or undermined borders. Either deepseated or superficially located keratin accumulations, the latter well visible within the hollows, were observed (Figs 1b, d; 2b, e). Incident light dermoscopy provided a 3 -dimensional view of the scars, highlighting variable scar depth levels along with additional hollows (Fig. 2c, f).

Histopathologically, DEP corresponded to a large, multi-loculated, superficially and horizontally-oriented hollow with dilated superficial openings. The cavity was lined by normal multilayered epithelium and filled with corneal lamellae, cellular debris, and amorphous material; there was no evidence of hair follicles (Table $\mathrm{SII}^{1}$ ).

\section{DISCUSSION}

The role of imaging in HS is to enhance the visualization and to better define the extension of typical cutaneous lesions, supporting diagnosis, and assessment of disease severity. Different imaging technologies providing objective information, such as ultrasound and magnetic resonance, may be used for this purpose $(3,4)$. Dermoscopy may be extended beyond pigmented skin lesions to various dermatological disorders, such as inflammatory 


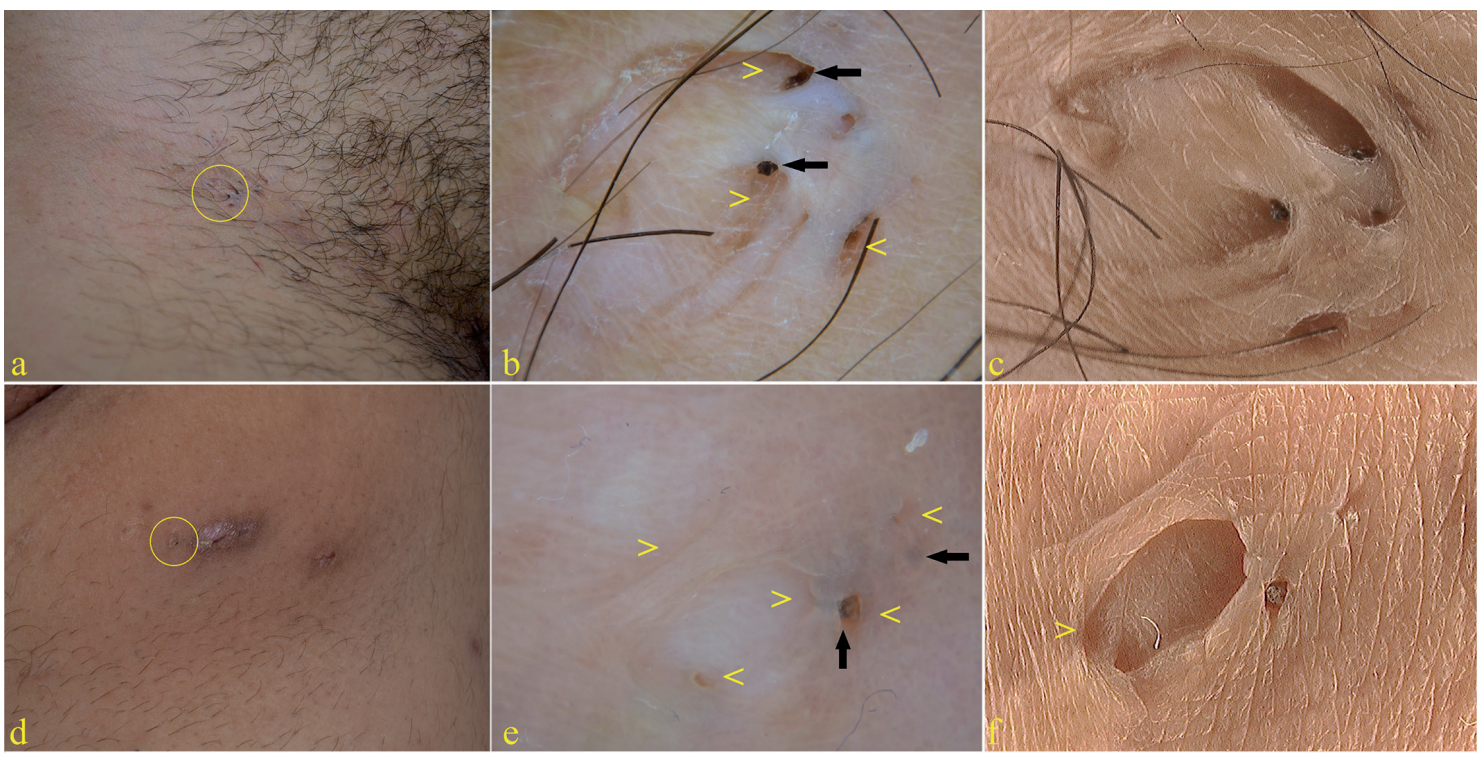

Fig. 2. Two further cases (Nos. 10 and 1) of hidradenitis suppurativa with pseudocomedones. Clinical picture of double-ended pseudocomedones $(a, d)$. Under polarized light dermoscopy, several irregular openings of variable size (arrowheads) and superficial and deep-seated keratin accumulations (black arrows) are seen embedded in a whitish cicatricial tissue (b, e). Incident light dermoscopy (c, f) highlights circinate (c) and bridging scars (f), as well as additional hollows (arrowhead).

and infectious diseases, as well as hair and nail abnormalities (5). So far, dermoscopy has not been used in the evaluation of HS.

DEP are considered a typical sign of HS that may often be overlooked (2). According to a new validated glossary, they should be named "keratin-filled interconnected multipores" (6). Under dermoscopy, DEP appear as coupled deepening hollows presenting a keratin mass at each end sometimes connected by a bluish tract detectable through a translucent, cicatricial tissue.

In our cases, we noted that all DEP resulted from the healing of previous inflammatory lesions, as confirmed by their constant presence within a cicatricial tissue. DEP may result from keratinization of the residual stump of 2 adjacent follicles undergoing cicatricial rearrangements (7) and the histopathological features observed in our cases confirm this assumption. Furthermore, using dermoscopy, we detected the presence of scars with different depth levels, suggesting a long-lasting, wax and wane tissue repair, as confirmed by all patients. We suggest that mechanical stress (friction), as recently supposed, may hypothetically play a role in triggering such relapsing inflammatory processes (8).

Histopathology of DEP showed cavities lined by normal multilayered epithelium and filled with corneal lamellae, cellular debris, and amorphous material, in which the hair follicles, which were destroyed by the inflammatory process, were no longer detectable. As a result, no hairs were observed on clinical and dermoscopy evaluation.

Differential diagnosis of DEP is mainly with open comedones (see Table SII ${ }^{1}$ ), which usually appear on the face and back of teenagers or in adult patients with acne. Both clinically and at dermoscopy they present as superficial, follicular papules with a central, roundish opening filled with a keratotic plug, generally overlying a regular flat epidermis. Depressed scars from previous acne lesions may be present, but not within the comedo. Histopathologically, open comedones appear as a widened hair follicle filled with keratin (9).

In conclusion, our study demonstrated that DEP are closely related to the presence of fibrosis and may be considered the outcome of the chronic and relapsing course of HS. Dermoscopy may enhance diagnostic accuracy by revealing findings not appreciable to the naked eye and may improve our understanding of some pathogenetic mechanisms underlying this ill-defined disorder.

The authors declare no conflicts of interest.

\section{REFERENCES}

1. Jemec GB, Kimball AB. Hidradenitis suppurativa: epidemiology and scope of the problem. J Am Acad Dermatol 2015; 73: S4-7.

2. Revuz JE, Jemec GB. Diagnosing hidradenitis suppurativa. Dermatol Clin 2016; 34: 1-5.

3. Wortsman $X$. Imaging of hidradenitis suppurativa. Dermatol Clin 2016; 34: 59-68.

4. Martorell A, Segura Palacios JM. Ultrasound examination of hidradenitis suppurativa. Actas Dermosifiliogr 2015; 106: 49-59.

5. Micali G, Lacarrubba F, Massimino D, Schwartz RA. Dermatoscopy: alternative uses in daily clinical practice. J Am Acad Dermatol 2011; 64: 1135-1146.

6. Lipsker D, Severac F, Freysz M, Sauleau E, Boer J, Emtestam L, et al. The $A B C$ of hidradenitis suppurativa: a validated glossary on how to name lesions. Dermatology 2016; 232: 137-142.

7. Margesson LJ, Danby FW. Hidradenitis suppurativa. Best Pract Res Clin Obstet Gynaecol 2014; 28: 1013-1027.

8. Boer J, Jemec GB. Mechanical stress and the development of pseudo-comedones and tunnels in hidradenitis suppurativa/ acne inversa. Exp Dermatol 2016; 25: 396-397.

9. Plewig G, Kligman AM. Acne and rosacea. 2nd edn. Berlin: Springer-Verlag, 1993. 